\title{
Human papillomavirus genotypes in cervical cancer and vaccination challenges in Zimbabwe
}

\author{
Nyasha Chin'ombe ${ }^{1 *}$, Natasha L Sebata', Vurayai Ruhanya ${ }^{1}$ and Hilda T Matarira ${ }^{2}$
}

\begin{abstract}
Cervical cancer is one of the major causes of morbidity and mortality in women in Zimbabwe. This is mainly due to the high prevalence of high-risk human papillomavirus (HPV) genotypes in the population. So far, few studies have been done that showed the presence of high-risk genital HPV genotypes such as 16, 18, 31, 33, 52,58 and 70 in Zimbabwean women with cervical cancer. The prevalence of HPV DNA in women with cervical cancer has been shown to range from $63 \%$ to $98 \%$. The high-risk HPV 16, 18, 31, 33 and 58 were the most common genotypes in all the studies. The introduction of the new HPV vaccines, HPV2 and HPV4, which protect against HPV genotypes 16 and 18 into Zimbabwe is likely to go a long way in reducing deaths due to cervical cancer. However, there are few challenges to the introduction of the vaccines. The target population for HPV vaccination is at the moment not well-defined. The other challenge is that the current HPV vaccines confer only type-specific (HPV 16 and 18) immunity leaving a small proportion of Zimbabwean women unprotected against other high-risk HPV genotypes such as 31,33 and 58 . Future HPV vaccines such as the nanovalent vaccine will be more useful to Zimbabwe as they will protect women against more genotypes.
\end{abstract}

\section{Introduction}

Human papillomaviruses (HPVs) are a group of highly ubiquitous double-stranded circular DNA viruses that infect cutaneous and mucosal surfaces [1]. They are divided into low-risk and high-risk genotypes [2]. The main low-risk genotypes are HPV genotypes $6,11,40$, $42,43,44,54,61,70,72,81$ and the main high-risk groups are HPV genotypes $16,18,31,33,35,39,45,51$, $52,56,58,59,68,73,82$. It is now well established that infection of the cervical tissue with the high-risk HPV genotypes is a necessary cause of cervical cancer in women [3-5]. At the moment, public knowledge of HPV and cervical cancer is still lacking in Zimbabwe. The lack of knowledge on cervical cancer and HPV was also found during our previous cervical cancer needs assessment study in 2 provinces of Zimbabwe a few years ago [6].

\section{The burden of cervical cancer in Zimbabwe}

Zimbabwe is a low-income country in Southern Africa and is bordered by Botswana, South Africa, Zambia and

\footnotetext{
* Correspondence: nyasha.chinombe@gmail.com

${ }^{1}$ Department of Medical Microbiology, University of Zimbabwe, A178,

Avondale, Harare, Zimbabwe

Full list of author information is available at the end of the article
}

Mozambique. According to the latest population census, Zimbabwe has a population of 12,5 million people of which approximately half are female. Nationally, the Ministry of Health and Child Care has the primary responsibility of providing health care services to the majority of the population, including maternal and reproductive health services such as prevention and treatment of cervical cancer. Worldwide, cervical cancer is the second most common malignancy in women [7]. Almost $80 \%$ of cervical cancer cases are found in low income level countries [8,9]. In most African countries, cervical cancer is a leading cause of death in women [10]. The age-standardised incidence rates of cervical cancer in Africa ranges from 42.7 to 12.1 per 100000 women [11]. In Zimbabwe, cervical cancer is an important reproductive health problem and is a major cause of mortality and morbidity in women than any other cancers [12]. It accounts for $32.2 \%$ of all female cancers and is the most common [12]. The ageadjusted incidence rate of cervical cancer in Zimbabwe is estimated at about 52.1 per 100,000 women and ageadjusted mortality rate is $43.1 \%$ [13]. The exact number of women suffering and dying from cervical cancer is likely to be higher than those quoted by the Zimbabwe National Cancer Registry as there are many women dying of the 
disease in the rural areas and are not reported. Some of the women who die have never attended a health facility up to the time of their death.

\section{HPV genotypes in cervical cancer in Zimbabwe}

In Zimbabwe, a number of studies have been done to evaluate high-risk HPV genotypes present in women with cervical cancer. Firstly, a cross-sectional study ( $\mathrm{n}=$ 119) was done to investigate the prevalence of low-risk and high-risk HPV genotypes in women with cervical cancer at two referral hospitals, Harare Central and Parirenyatwa Hospitals in Harare in Zimbabwe [14]. Using the Hybrid Capture assay, HPV DNA was detected in $63 \%$ of the cervical swabs. The prevalence of any of the high-risk HPV genotypes $(16,18,31,33,35$, $45,51,52$ and 56$)$ was $51 \%$. The low-risk HPV genotypes $(6,11,42,43$ and 44$)$ were detected in $26 \%$ of the samples. In this study, dual infection with both the low-risk and high-risk HPV genotypes was found in 14\% of the cases. This was the first study to show an association of certain HPV genotypes with cervical cancer in Zimbabwe. In a second study in Harare, the presence of HPV genotypes in cervical swabs and urine collected from Zimbabwean women $(n=43)$ who had cervical cancer was conducted using restriction fragment length polymorphism-polymerase chain reaction [RFLP-PCR] [15]. Of all the women studied, 98\% and 72\% had HPV DNA in cervical swabs and urine samples respectively. In this study, the high-risk HPV 16 was the most prevalent genotype and was found in $59 \%$ of the cervical samples. HPV 33 was found in $31 \%$ of the samples followed by HPV 18 (14\%), HPV 31 (2\%) and HPV 58 (2\%). It was also noted in this study that the HPV genotypes found in the urine samples were the same as those found in the cervical samples. Of the 28 urines samples typed, $61 \%$, $16 \%, 13 \%$ and $3 \%$ had HPV 16, 33, 18 and 31 genotypes respectively. According to this study, HPV 33 was the second commonest genotypes found in Zimbabwe and is not covered by the current two HPV vaccines on the market.

In a third study with 98 Zimbabwean women with cervical cancer in Harare, HPV genotypes were also investigated [16]. The HPV DNA was detected in $97 \%$ of the samples. Of the cases, HPV 16, 33, 18 and 31 genotypes were found in $61 \%, 39 \%, 18 \%$ and $4 \%$ of the samples respectively. HPV 35 and 58 were also found in some samples. It was also noted in this study that some patients who were dually infected with both HPV 16 and HPV 33 and most of them were young (10-13 age-group).

Another study was conducted to determine cervical HPV incidence in a cohort of $2040 \mathrm{HIV}$-negative Zimbabwean women [17]. The prevalence of HPV genotypes, 58, 16, 70, $18,33,53,52$ and 31 was $5.0 \%, 4.7 \%, 2.4 \%, 2.3 \%, 2.0 \%$, $1.8 \%, 1.3 \%$ and $1.3 \%$ respectively [17]. This study showed that the high-risk HPV 58 was more common than genotype 16 or 18 that are covered by the current HPV vaccines.
Overall, these few studies mentioned above highlight the need to have HPV vaccines in Zimbabwe that will cover all most prevalent genotypes.

\section{Risk factors of cervical cancer in Zimbabwe}

It is now generally agreed that persistent infection by high-risk HPV genotypes is the major cause of cervical cancer [18]. There are several risk factors that universally predispose women to acquiring high-risk HPVs that may cause cervical cancer [19]. The factors include multiparity, early age of first intercourse, multiple sexual partners, poor genital hygiene, use of oral steroid contraceptives, cigarette smoking, some dietary factors and infection with other sexually transmitted pathogens such as Chlamydia trachomatis and herpes simplex virus which cause chronic cervicovaginal inflammation [20-23]. In addition to the above factors, there are other cofactors such as host genetic factors and immunodeficiency that are considered to be also important for development and progression of cervical cancer $[20,24]$. Other factors such as race and ethnicity are also important risk factors of cervical cancer [25]. African women are at a higher risk of developing cervical cancer than their Caucasian counterparts [22,26]. Our research group at the University of Zimbabwe also previously carried out a national cervical cancer needs assessment study of Zimbabwean (African) women in two provinces [6]. Some of the risk factors of cervical cancer were investigated. From the study, it was noted that $76 \%$ of cervical cancer in Zimbabwe presented late at health care facilities. The high percentage of women (44\%) in the study did not use contraceptives such as condoms that can protect against HPV acquisition. Only $4 \%$ of married couples used barrier/condoms. The mean parity was 5 children. Sexual activity in Zimbabwean girls was found to start at 15 and this was likely to predispose them to HPV infection at an early age. From the study, it was also noted that knowledge of cervical cancer and HPVs was very low in the population. The study highlighted some of the risk factors that predisposed women to HPV infection and the gaps in prevention of cervical cancer in Zimbabwe.

\section{HPV vaccination and challenges in Zimbabwe}

Two HPV vaccines have recently been developed to prevent cervical cancer in women [27,28]. In Zimbabwe, considerations are now being made to vaccinate girls and women against HPV using the two recently licensed subunit vaccines, HPV2 and HPV4. The vaccines are now available in the private sector and will be introduced into the public health institutions soon. HPV2 is a bivalent vaccine that prevents mainly HPV-16 and HPV18 , while HPV4 is a quadrivalent vaccine that prevents infection by HPV-16, HPV-18, HPV 6 and HPV 11 genotypes. The two vaccines have been shown to be effective and efficacious in preventing cervical cancer caused 
by HPV 16 and 18 genotypes and genital warts caused by HPV 6 and 11 genotypes [29-32]. Although the two vaccines can be very helpful in reducing cervical cancer mortality in the long-term, their introduction in Zimbabwe is likely to meet several challenges. Since the two vaccines only target HPV genotypes $6,11,16$, and 18 , the vaccines may not be effective in protecting against other HPV genotypes that are common in Zimbabwe and cause cervical cancer. According to studies mentioned above, the highrisk HPV genotypes 31, 33 and 58 were also found in a substantial proportion of women with cervical cancer [14-16]. Women infected with such genotypes will not be fully protected from getting cervical cancer by the current vaccines. This challenge has also been observed in other African countries such as Zambia, Cameroun, Mozambique and Senegal where other non- 16 and 18 genotypes were prevalent [33-36]. Although cross-protection against multiple genotypes by the current HPV vaccines may occur, it is not absolute [37-39]. The challenge therefore confirms the importance of developing HPV vaccines for genotypes common in African women. The new HPV nanovalent vaccine still in clinical trials [40] will be more useful in Zimbabwe and other Sub-Saharan African countries since it may protect against more HPV genotypes $(6 / 11 / 16 / 18 /$ $31 / 33 / 45 / 52 / 58$ ).

There are other HPV vaccination challenges in Zimbabwe. The target group for HPV vaccination has not yet been defined. Generally, girls should be targeted for HPV vaccination before the onset of sexual activities [41]. No studies on HPV infection in girls or boys of this age-group have been done in Zimbabwe. Epidemiological studies are still required to ascertain the HPV prevalence by age and sex in Zimbabwe. The other challenge to HPV vaccination in Zimbabwe is the prohibitive cost ( $\$ 180$ - $\$ 300$ for 3 doses in the private health care sector) of the vaccines to most people. Although the cost is high, the vaccines are readily available in the private sector. In the public health care sector, government or donor funding may have to subsidize the vaccines if more girls and women are to be reached. The funding for an HPV Vaccine Demonstration Project has been sourced from donors such as Global Alliance for Vaccine and Immunization (GAVI), UNICEF, WHO and UNFPA. The HPV vaccines will be introduced to two districts of Marondera and Beitbridge and will be targeted to adolescent girls aged 10 years. The government of Zimbabwe will assist with funding for the implementation of the project. It is hoped that the demonstration project will provide data that can be used for future national HPV vaccine rollout.

In Zimbabwe, as in most developing countries, there are no national cervical cancer screening or HPV testing programmes. Although $80 \%$ of all cervical cancers occur in developing countries, only about $5 \%$ of the at-risk women are screened for cervical cancer [42]. Screening of cervical cancer using cytology, visual inspection as well as HPV testing can reduce the high mortality in women in Zimbabwe. It has been suggested that HPV testing and cytology together would increase the chance of detecting cervical cancer by about 35\% [43]. No services for HPV testing in public and private sector are available. Cervical cancer prevention and control through screening and HPV vaccination should therefore be a national priority if women are to be saved from dying from cervical cancer, a preventable disease.

\section{Conclusion}

Cervical cancer caused by high-risk HPV genotypes accounts for substantial morbidity and mortality in Zimbabwe. The government is now planning to introduce HPV vaccines in girls in 2014 and the potential usefulness of these vaccines cannot be underestimated. Although there are few challenges, the HPV vaccines are likely to go a long way in reducing the prevalence of cervical cancer in Zimbabwean women.

\section{Competing interests}

The authors declare no competing interest.

\section{Authors' contributions}

All the authors contributed to the writing of the manuscript. All authors read and approved the final manuscript.

\section{Acknowledgements}

The authors acknowledge support from the Zimbabwe National Family Planning, International Parenthood Federation and the University of Zimbabwe's Departments of Medical Microbiology and Chemical Pathology.

\section{Author details}

${ }^{1}$ Department of Medical Microbiology, University of Zimbabwe, A178, Avondale, Harare, Zimbabwe. ²Department of Chemical Pathology, University of Zimbabwe, A178, Avondale, Harare, Zimbabwe.

Received: 15 November 2013 Accepted: 31 March 2014

Published: 13 May 2014

\section{References}

1. zur Hausen $\mathrm{H}$ : Papillomavirus and cancer: from basic studies to clinical application. Nat Rev Cancer 2002, 2:342-350.

2. Muñoz N, Bosch FX, de Sanjosé S, Herrero R, Castellsagué X, Shah KV, Snijders PJ, Meijer CJ, International Agency for Research on Cancer Multicenter Cervical Cancer Study Group: Epidemiologic classification of human papillomavirus types associated with cervical cancer. N Engl J Med. 2003, 348:518-527.

3. Bosch FX, Lorincz A, Muñoz N, Meijer CJLM, Shah KV: The causal relation between human papillomavirus and cervical cancer. J Clin Pathol 2002, 55:244-265.

4. Muñoz N, Bosch FX, Castellsagué X, Díaz M, de Sanjose S, Hammouda D, Shah KV, Meijer CJ: Against which human papillomavirus types shall we vaccinate and screen? The international perspective. Int J Cancer. 2004, 111:278-285.

5. Clifford GM, Smith JS, Aguado T, Franceschi S: Comparison of HPV type distribution in high-grade cervical lesions and cervical cancer: a meta-analysis. Br. J. Cancer 2003, 89:101-105.

6. Chin'ombe N, Matarira HT, Chidume J: Prevention of Cervical Cancer in Zimbabwe Report: A pilot needs assessment study of Masvingo and Manicaland provinces. Harare, Zimbabwe: University of Zimbabwe; 2000.

7. Sankaranarayanan R, Ferlay J: Worldwide burden of gynaecological cancer: the size of the problem. Best Pract Res Clin Obstet Gynaecol. 2006, 20:207-225. 
8. Termrungruanglert W, Havanond P, Khemapech N, Lertmaharit S, Pongpanich S, Khorprasert C, Taneepanichskul S: Cost and effectiveness evaluation of prophylactic HPV vaccine in developing countries. Value Health 2012, 15(1 Suppl):S29-34.

9. Parkin DM, Sitas F, Chirenje M, Stein L, Abratt R, Wabinga H: Part I: Cancer in Indigenous Africans - burden, distribution, and trends. Lancet Oncol 2008, 9:683-692.

10. Parkin DM, Pisani P, Ferlay J: Estimates of the worldwide incidence of 25 major cancers in 1990. Int J Cancer 1999, 80:827-841.

11. Louie KS, de Sanjose S, Mayaud P: Epidemiology and prevention of human papillomavirus and cervical cancer in sub-Saharan Africa: a comprehensive review. Trop Med Int Health 2009, 14:1287-302.

12. Registry ZNC: Pattern of cancer in Zimbabwe. Harare, Zimbabwe: Annual Report; 2010.

13. WHO/ICO Information Centre on HPV and Cervical Cancer: HPV and cervical cancer in the 2007 report. Vaccine 2007, 25(S3):C1-230.

14. Chirara M, Stanczuk GA, Tswana SA, Nystrom L, Bergstrom S, Moyo SR, Nzara MJ: Low risk and high risk human papillomaviruses (HPVs) and cervical cancer in Zimbabwe: epidemiological evidence. Cent Afr J Med 2001, 47:32-35.

15. Stanczuk GA, Kay P, Allan B, Chirara M, Tswana SA, Bergstrom S, Sibanda EN, Williamson AL: Detection of human papillomavirus in urine and cervical swabs from patients with invasive cervical cancer. J Med Virol 2003, 71:110-114.

16. Stanczuk GA, Kay P, Sibanda E, Allan B, Chirara M, Tswana SA, Bergstrom S, Williamson AL: Typing of human papillomavirus in Zimbabwean patients with invasive cancer of the uterine cervix. Acta Obstet Gynecol Scand 2003, 82:762-766

17. Fukuchi E, Sawaya GF, Chirenje M, Magure T, Tuveson J, Ma Y, Shiboski S, Da Costa M, Palefsky J, Moscicki AB, Makunike-Mutasa R, Chipato T, Smith-McCune KK: Cervical human papillomavirus incidence and persistence in a cohort of HIV-negative women in Zimbabwe. Sex Transm Dis 2009, 36:305-311.

18. Trottier H, Mahmud SM, Lindsay L, Jenkins D, Quint W, Wieting SL, Schuind A, Franco EL, GSK HPV-001 Vaccine Study Group: Persistence of an incident human papillomavirus infection and timing of cervical lesions in previously unexposed young women. Cancer Epidemiol Biomarkers Prev 2009, 18:854-862.

19. Schiffman M, Castle PE, Jeronimo J, Rodriguez AC, Wacholder S: Human papillomavirus and cervical cancer. Lancet 2007, 370:890-907.

20. Chou P: Review on risk factors of cervical cancer. Zhonghua Yi Xue Za Zhi 1991, 48:81-88.

21. Schiffman MH, Brinton LA: The epidemiology of cervical carcinogenesis. Cancer 1888-1901, 1995:76.

22. Franco EL: Epidemiology of uterine cancers. In Cytopathology of the uterus. 2nd edition. Edited by Meisels A, Morin C. Chicago: American Society of ClinicalPathologists; 1997:301-324

23. Winkelstein W: Smoking and cervical cancer: current status - a review. Am J Epidemiol 1990, 131:945-957.

24. Moore EE, Wark JD, Hopper JL, Erbas B, Garland SM, CeCaGeEn Study Group: The roles of genetic and environmental factors on risk of cervical cancer: a review of classical twin studies. Twin Res Hum Genet 2012, 15:79-86.

25. Castellsagué X, Díaz M, de Sanjosé S, Muñoz N, Herrero R, Franceschi S, Peeling RW, Ashley R, Smith JS, Snijders PJ, Meijer CJ, Bosch FX, International Agency for Research on Cancer Multicenter Cervical Cancer Study Group: Worldwide human papillomavirus etiology of cervical adenocarcinoma and its cofactors: implications for screening and prevention. J Natl Cancer Inst 2006, 98:303-315.

26. Seth $P$, Wingood GM, Robinson LS, Diclemente RJ: Exposure to high-risk genital human papillomavirus and its association with risky sexual practices and laboratory-confirmed chlamydia among African-American women. Womens Health Issues 2009, 19:344-351.

27. Wright TC Jr: Current status of HPV vaccination recommendation. HPV Today 2008, 14:8-9.

28. Kawana K, Yasugi T, Taketani Y: Human papillomavirus vaccines: current issues \& future. Indian J Med Res. 2009, 130:341-347.

29. Einstein MH, Baron M, Levin MJ, Chatterjee A, Edwards RP, Zepp F, Carletti I, Dessy FJ, Trofa AF, Schuind A, Dubin G: Comparison of the immunogenicity and safety of Cervarix and Gardasil human papillomavirus (HPV) cervical cancer vaccines in healthy women aged 18-45 years. Hum Vaccin 2009, 5:705-719.
30. Villa LL, Costa RL, Petta CA, Andrade RP, Ault KA, Giuliano AR, Wheeler CM, Koutsky LA, Malm C, Lehtinen M, Skjeldestad FE, Olsson SE, Steinwall M, Brown DR, Kurman RJ, Ronnett BM, Stoler MH, Ferenczy A, Harper DM, Tamms GM, Yu J, Lupinacci L, Railkar R, Taddeo FJ, Jansen KU, Esser MT, Sings HL, Saah AJ, Barr E: Prophylactic quadrivalent human papillomavirus (types 6, 11, 16, and 18) L1 virus-like particle vaccine in young women: a randomised double-blind placebo-controlled multicentre phase II efficacy trial. Lancet Oncol 2005, 6:271-278.

31. Siddiqui MA, Perry CM: Human papillomavirus quadrivalent (types 6,11 , $16,18)$ recombinant vaccine (Gardasil). Drugs 2006, 66:1263-1271.

32. Villa LL, Ault KA, Giuliano AR, Costa RL, Petta CA, Andrade RP, Brown DR, Ferenczy A, Harper DM, Koutsky LA, Kurman RJ, Lehtinen M, Malm C, Olsson SE, Ronnett BM, Skjeldestad FE, Steinwall M, Stoler MH, Wheeler CM, Taddeo FJ, Yu J, Lupinacci L, Railkar R, Marchese R, Esser MT, Bryan J, Jansen KU, Sings HL, Tamms GM, Saah AJ, Barr E: Immunologic responses following administration of a vaccine targeting human papillomavirus Types $6,11,16$, and 18 . Vaccine 2006, 24:5571-5583.

33. Sahasrabuddhe W, Mwanahamuntu MH, Vermund SH, Huh WK, Lyon MD, Stringer JS, Parham GP: Prevalence and distribution of HPV genotypes among HIV-infected women in Zambia. Br J Cancer 2007, 96:1480-1483.

34. Desruisseau AJ, Schmidt-Grimminger D, Welty E: Epidemiology of HPV in HIV-positive and HIV-negative fertile women in Cameroon. West Africa. Infect Dis Obstet Gynecol 2009, 2009:810596.

35. Castellsague XC, Menendez MP, Loscertales JR, Kornegay F, dos Santos FX, Gomez-Olive B, Lloveras N, Abarca N, Vaz A, Barreto X, Bosch FX, Alonso P: Human papillomavirus genotypes in rural Mozambique. Lancet 2001, 358:1429-1430.

36. Xi L, Toure FP, Critchlow CW, Hawes SE, Dembele B, Sow PS, Kiviat NB: Prevalence of specific types of human papillomavirus and cervical squamous intraepithelial lesions in consecutive, previously unscreened, West-African women over 35 years of age. Int. J. Cancer 2003, 103:803-809.

37. Jenkins D: A review of cross-protection against oncogenic HPV by an HPV-16/18 AS04-adjuvanted cervical cancer vaccine: importance of virological and clinical endpoints and implications for mass vaccination in cervical cancer prevention. Gynecologic Oncology 2008, 110:S18-S25.

38. Lu B, Kumar A, Castellsagué X, Giuliano AR: Efficacy and safety of prophylactic vaccines against cervical HPV infection and diseases among women: a systematic review \& meta-analysis. BMC Infect Dis 2011, 11:13.

39. Harper DM, Franco EL, Wheeler CM, Moscicki AB, Romanowski B, RoteliMartins CM, Jenkins D, Schuind A, Costa Clemens SA, Dubin G: HPV Vaccine Study group. Sustained efficacy up to 4.5 years of a bivalent L1 virus-like particle vaccine against human papillomavirus types 16 and 18: follow-up from a randomised control trial. Lancet 2006, 367:1247-1255.

40. Drolet M, Laprise JF, Boily MC, Franco EL, Brisson M: Potential cost-effectiveness of the nonavalent human papillomavirus (HPV) vaccine. Int J Cancer 2014, 134:2264-2268

41. Agosti JM, Goldie SJ: Introducing HPV vaccine in developing countries key challenges and issues. N Engl J Med 2007, 356:1908-1910.

42. Pontén J, Adami HO, Bergström R, Dillner J, Friberg LG, Gustafsson L, Miller AB, Parkin DM, Sparén P, Trichopoulos D: Strategies for global control of cervical cancer. Int J Cancer 1995, 60:1-26.

43. Naucler P, Ryd W, Törnberg S, Strand A, Wadell G, Elfgren K, Rådberg T, Strander B, Forslund O, Hansson BG, Hagmar B, Johansson B, Rylander E, Dillner J: Efficacy of HPV DNA testing with cytology triage and/or repeat HPV DNA testing in primary cervical cancer screening. J Natl Cancer Inst 2009, 101:88-99.

doi:10.1186/1750-9378-9-16

Cite this article as: Chin'ombe et al: Human papillomavirus genotypes in cervical cancer and vaccination challenges in Zimbabwe. Infectious Agents and Cancer 2014 9:16. 